International Association for the Psychology of Language Learning (IAPLL)

Journal for the Psychology of Language Learning

ISSN: 2642-7001. http://www.iapll.com/journal

Issue 1, June 2019, pp. 142-147

\title{
Book Review: Positive Psychology Perspectives on Foreign Language Learning and Teaching. Edited Collection by Danuta Gabryś-Barker and Dagmara Galajda.
}

Reviewed by Sonja Babic, University of Graz, Austria

Traditionally, within psychology, the focus has been on the negative aspects of human functioning and how to improve and treat problems. Positive Psychology (PP) emerged to balance the field by ensuring a consideration of both positive and negative dimensions; to examine what goes well in life as well as instances of disorder and dysfunction. As a result, PP concentrates on "positive emotion, positive character traits, and institutions that enable individuals to flourish" (MacIntyre, 2016, p. 3). PP has recently started gaining researchers' attention in language learning and teaching (MacIntyre, Gregersen, \& Mercer, 2016), although it is still in its infancy within Second Language Acquisition (SLA). This volume is one of the first few edited collections to address this nascent field. It comprises theoretical, practical and empirical studies of foreign language learning and teaching through the lens of PP. It encompasses four main sections, namely, introducing PP in SLA; focus on learners: positive interventions; focus on teachers: personal and professional wellbeing; and, focus on assessment: achievement and success.

The first section of the book aims at introducing positive psychology in SLA and consists of three chapters. In the first chapter, Peter D. MacIntyre identifies key trends in current research in PP and SLA. MacIntyre suggests that PP has achieved a good start in SLA, which is being increasingly recognized in the field as it fits perfectly with modern language pedagogy. He highlights four key contributions; namely, distinguishing between positive and negative emotions; examining and applying the model of character strengths in SLA; extending 
Seligman's (2011) PERMA model of wellbeing (which stands for positive emotions, engagement, meaning, positive relationships, and accomplishment) to Oxford's (2016) EMPHATICS; and, highlighting the concept of Csikszentmihalyi's (1990) “flow” in SLA. MacIntyre claims that SLA can benefit greatly from considering PP; however, he emphasizes the need "to balance theory, research, and practice as we move forward along this potentially exciting path" (p. 17). In the second chapter, Rebecca Oxford expands on PERMA model of wellbeing and offers EMPHATICS model. The model encompasses nine concepts: E - emotions and empathy; $\mathrm{M}$ - meaning and motivation; $\mathrm{P}$ - perseverance, resilience, hope, and optimism; A - agency and autonomy; $\mathrm{T}$ - time; $\mathrm{H}$ - hardiness and habits of mind; I - intelligences; $\mathrm{C}$ character strengths; and, S - self-factors such as self-efficacy, self-concept, self-esteem, and selfverification. This is an exhaustive wellbeing model containing constructs that can empower language learning processes. In the last chapter of this section, Hanna Komorowska explores diverse interpretations of PP aspects in SLA or foreign language teaching (FLT), and what mythology, religion, psychology, and sociology suggest in terms of understanding the impact of positive and negative affect on language learners. Komorowska found that four learners' personality characteristics seem to be particularly important in coping with difficulty in language learning: self-efficacy, lack of sensitivity to negative stimulation, resilience, and the sense of coherence, which is described as the "ability to identify both the content and the value of messages" (p. 51).

The second and largest section of the edited collection encompasses eight chapters, and concerns language learners and PP interventions (PPI). PPIs are tools and activities that "teach individuals ways to increase their positive thinking, positive affect, and positive behaviors" (Layous, Chancellor, Lyubomirsky, Wang, and Doraiswamy, 2011, p. 675). Investigating how to empower learners and their learning has dominated SLA research, which is mirrored in the larger number of chapters in this section.

In the first chapter of the second section, Tammy Gregersen reports on six language learner PPIs, respectively - gratitude, altruism, music, pets, laughter, and exercise. Gregersen found that experiencing positive emotions can facilitate language learning, help learners to enjoy the process, and create greater stamina for their language learning endeavours. In the next chapter, Liliana Piasecka investigates another PPI - activating character strengths through poetic encounters in foreign language. According to Piasecka, character strengths such as creativity, 
courage, curiosity, open-mindedness, zest, self-control, social intelligence, and appreciation of beauty are tightly connected to self-efficacy and life satisfaction. PPIs that help language learners in higher education to set and achieve their learning goals and practice self-regulation of emotion strategies are addressed by Sylwia Kossakowska-Pisarek in the following chapter. The study took place at the University of Warsaw, in which 229 students of Legal English course participated. She found that PPIs in turn could facilitate language learning and help students reach optimal level of functioning; however, further research in this area, according to the author, is certainly called for. Andrea Dallas and Mary Hatakka, in the next chapter, report on two iterations of a workshop (face-to-face and online), which focuses on PPIs that encourage freshmen L2 students to develop a sense of personal responsibility (PR) toward their studies. Dallas and Hatakka discovered that students need more time, feedback, and support to create and apply PR within and beyond their academic lives. In the following chapter, Ewa Guz and Małgorzata Tetiurka examine the relationship between teachers and learners, including factors that contribute to positive emotions and learner engagement. Forty-five Polish pre-service teachers from English Department at John Paul II Catholic University of Lublin participated in the study. The teachers were instructed to design their own lesson plan in accordance with the curriculum, and to record and transcribe their own lesson. The authors merely focused on the extent and intensity of learner engagement. They found that learner engagement and positive emotions are closely related to teachers' positive emotions and mindset, which consequently encourage learners and create overall positive learning atmosphere. The authors also observed that certain kinds of pedagogical interventions are evidently more engaging than others. In the succeeding chapter, Danuta Gabryś-Barker looks into the effects of classroom climate on foreign language learning, personal development, and wellbeing of teachers and learners. GabryśBarker's findings suggest ways in how to improve classroom climate through creating certain codes that teachers and learners agree upon. These codes (rights and duties that could be grounded in PP) put equal responsibility on teachers and learners and thus could positively influence foreign classroom atmosphere. In the next chapter, Katarzyna Ożańska-Ponikwia explores personality characteristics and emotional intelligence (EI) in relation to learning a foreign language in immigrant and non-migrant contexts. The findings show that a considerable number of personality and EI traits is related to the variables such as openness, self-esteem, and wellbeing. The last chapter in this section reports on a study conducted by Beata Malczewska- 
Webb on the positive sides of living and studying in Australia for 597 international students. Malczewska-Webb found that the factors that contribute most to positive experiences of these students are environment, social aspects and fun, and healthy lifestyle.

The third section of this edited collection focuses on teacher personal and professional wellbeing and consists of four chapters. Sarah Mercer, Pia Oberdorfer, and Mehvish Saleem's chapter opens the section. The authors argue that teacher psychology and wellbeing play a crucial role in language learning processes and note a relative absence of research about teacher psychology. They further emphasize the crucial importance of supporting (language) teachers in their "rewarding but demanding" (p. 221) jobs and discuss possible ways to protect the teachers and promote their professional wellbeing in various professional settings. In the following chapter, Anna Ligia Wirczorek explores factors that contribute to stress among foreign language teachers and discusses how inhibitions and self-esteem influence the language teachers and their professional wellbeing in this study. Another under-investigated aspect of teacher psychology is addressed by Elena Gallo in the following chapter. The author explores the ways in which university language teachers approach their professional development (PD), and the impact of affective factors on teacher professional development (TPD). Gallo identifies four teacher goals; namely, instructional, occupational, developmental and affective-emotional goals, and three appraisal patterns in teacher learning behavior. She also discovered that positive emotions and TPD are closely related, and calls for further research in this area. In the final chapter of this section, Teresa Maria Włosowicz investigates university students’ expectations regarding their foreign language teachers, including the teaching and learning process. While some students prefer a teacher to be strict, the majority of students in this study highlight the importance of a good relationship with the teacher, who they feel should be patient and empathetic and, in terms of skills development, emphasise speaking practice.

The five chapters in the last section of this book draw attention to the implementation of PP in foreign language assessment, achievement and success. In the first chapter, Monika Kusiak-Pisowacka reports on how to improve assessment experience for both learners and teachers. The author offers valuable insights and suggests ways to enhance positive experiences of language assessment. Agnieszka Strzałka, in the next chapter, explores whether earning academic credits in an intercultural communication university course can be enjoyable. It was found that developing students' strengths such as curiosity, zest, and teamwork contribute to 
more pleasurable learning experience. Next, Jan Zalewski explores ways to help low-achieving students, who would traditionally be excluded from tertiary education, to achieve academic success. Zalewski's findings suggest explicit literacy instruction can be enormously helpful in ensuring positive educational experiences for the low-achieving students. In the succeeding chapter, Ewa Piechurska-Kuciel examines the self-regulated efficacy and attainment of 621 foreign language students in a Polish grammar school. Piechurska-Kuciel found that students with higher-level of self-regulated efficacy differ from the lower-level students in terms of personal goals, grade achievement, and their own perception of control. Piotr Szymczak's chapter closes the last section and the book. Szymczak explores ways to improve translation competitions based on the PERMA model of wellbeing. According to Szymczak, the most important aspects are fair assessment procedure, providing feedback, and inviting competitors not to experience the competition as a test of their skills, but as a "new experience and an opportunity to make new contacts, turning a test into a celebration of their skills and knowledge" (p. 364).

Together, these chapters offer a rich introduction to the field, but it is notable that there remains a strong focus on individual psychology with relatively little consideration of social or embodied aspects of psychology. Perhaps future studies in PP and SLA could include contemplations of social, collective and embodied perspectives on the psychologies of both learners and teachers. Finally, a concluding chapter that draws together the main themes across the chapters would have been a valuable addition in highlighting important issues and future directions for this relatively young field of research. That said, this collection remains an invaluable source of knowledge covering a range of empirical, theoretical and practical concerns for teachers and learners making it a rich contribution to the emergent field of PP in SLA.

\section{Full Publication Details}

Title: Positive Psychology Perspectives on Foreign Language Learning and Teaching.

Editors: Danuta Gabryś-Barker and Dagmara Galajda

Date: 2016

Publisher: Springer International Publishing, Switzerland.

Number of pages: 366 


\section{Number of chapters: 20}

ISBN-10: 3319329537

ISBN-13: 9783319329536

\section{References}

Csikszentmihalyi, M. (1990). Flow: The psychology of optimal experience. New York, NY: Harper and Row.

Layous, K., Chancellor, J., Lyubomirsky, S., Wang, L., \& Doraiswamy, P. M. (2011). Delivering happiness: Translating positive psychology intervention research for treating major and minor depressive disorders. The Journal of Alternative and Complementary Medicine, 17(8), 675-683. doi:10.1089/acm.2011.0139

MacIntyre, P. D. (2016). So far so good: An overview of positive psychology and its contributions to SLA. In Gabryś-Barker, D., \& Gałajda, D. (Eds.), Positive psychology perspectives on foreign language learning and teaching (pp. 3-20). Cham, Switzerland: Springer International Publishing.

Oxford, R. L. (2016). Powerfully Positive: Searching for a model of language learner well-being. In Gabryś-Barker, D., \& Gałajda, D. (Eds.), Positive psychology perspectives on foreign language learning and teaching (pp. 21-38). Switzerland: Springer International Publishing.

MacIntyre, P. D., Gregersen, T., \& Mercer, S. (2016). Positive psychology in SLA. Bristol, UK: Multilingual Matters.

Seligman, M. E. P. (2011). Flourish: A visionary new understanding of happiness and wellbeing. New York, NY: Atria Books. 